\title{
Efficacy of different cooling methods for capture-induced hyperthermia in antelope
}

\author{
Joanna Sawicka', Andrea Fuller', Linda G. Fick', \\ Robyn S. Hetem ${ }^{1}$ \& Leith C.R. Meyer ${ }^{1,2 *}$ \\ ${ }^{1}$ Brain Function Research Group, School of Physiology, University of the Witwatersrand, \\ 7 York Road, Parktown, 2193 South Africa \\ ${ }^{2}$ Department of Paraclinical Science, Faculty of Veterinary Science, University of Pretoria, \\ Private Bag X04, Onderstepoort, 0110 South Africa \\ Received 2 September 2014. To author for revision 26 October2014. Accepted 25 November 2014
}

\begin{abstract}
The capture of wild animals is a stressful event which may cause a capture-induced hyperthermia, resulting in morbidity or mortality. We investigated whether various cooling techniques were effective at lowering the body temperature of hyperthermic animals. To achieve this, we implanted miniature temperature-sensitive data loggers into the abdomens of 12 blesbok (Damaliscus pygargus phillipsi). Five animals were cooled by dousing with water of different temperatures $\left(4^{\circ} \mathrm{C}, 17^{\circ} \mathrm{C}, 28^{\circ} \mathrm{C}\right)$ and fanning after dousing with $28^{\circ} \mathrm{C}$ water. Seven animals were cooled by ice-packs, a fine mist spray of $28^{\circ} \mathrm{C}$ water, intravenous (IV) infusion of one litre of $4^{\circ} \mathrm{C}$ saline solution or $28^{\circ} \mathrm{C}$ water-dousing. The body temperature after capture was significantly elevated to as high as $41^{\circ} \mathrm{C}$ to $42^{\circ} \mathrm{C}$. Water-dousing interventions significantly decreased minimum body temperature but there was no difference in the minimum body temperature reached or the magnitude of cooling between the different water temperatures or by the addition of fanning. The ice-packs also lowered body temperature, whereas mist spraying did not. The use of ice packs and dousing with water between $4^{\circ} \mathrm{C}$ and $28^{\circ} \mathrm{C}$ were the most effective techniques to reduce capture-induced hyperthermia in blesbok. Water-dousing, when done appropriately, is the most practical and effective method to cool an animal with capture-induced hyperthermia.
\end{abstract}

Key words: water-dousing, blesbok, ice-packs, stress, body temperature, hyperthermia.

\section{INTRODUCTION}

Capture is a necessary practice in the management and conservation of wildlife but often elicits adverse physiological changes in animals (Foster 2005). These physiological changes, which include alterations in body temperature, acid-base balance, tissue growth and maintenance of immunity (Kock, Jessup, Clark \& Franti, 1987; Cattet, Christison \& Caulkett, 2003), may result in morbidity and/or mortality (Ganhao, Hattingh \& Pitts, 1988). A precipitous body temperature increase, termed captureinduced hyperthermia (Meyer, Hetem, Fick, Mitchell \& Fuller, 2008a; Meyer, Hetem, Fick, Mitchell \& Fuller, 2008b), is probably the most conspicuous and consistent adverse effect of capture in wildlife.

The severity of the capture-induced hyperthermia, as reflected by the magnitude and duration of the body temperature increase, is associated with the likelihood of organ damage, rhabdomyolysis, alterations in electrolyte balance, increased oxidative

*To whom correspondence should be addressed. E-mail: leith.meyer@up.ac.za stress and possible death (Kosaka et al., 2004; Kock \& Meltzer, 2006). Capture-induced hyperthermia 'is one of the primary indications for the development of capture myopathy' (Drew, 1996), a potentially lethal condition associated with capture.

The mechanisms underlying the increase in body temperature during capture-induced hyperthermia are not fully understood, but a primary factor appears to be the sympathetic stress response; even animals engaging in low levels of activity during capture, and at mild ambient temperatures, may develop severe hyperthermia (Meyer, Hetem, Fick, Mitchell \& Fuller, 2008a). The consistent finding of elevated body temperatures in captured animals supports the idea that psychological stress has a major role in the development of capture-induced hyperthermia (Meyer, Hetem, Fick, Mitchell \& Fuller, 2008a). While there are efforts to reduce stress during capture, for example by the use of rapidly acting chemical immobilizing agents, most capture events, by their nature, are likely to induce an 
acute stress response, and therefore some degree of hyperthermia, in captured individuals (Meyer, Hetem, Fick, Mitchell \& Fuller, 2008a).

Given that capture-induced hyperthermia in some individuals may be severe, one way to improve animal welfare is to physically cool captured animals. Recommendations for cooling captured animals include placing the animals in the shade and dousing with water (Meltzer, Burroughs \& Morkel, 2006b), using portable mist sprayers and rapid intravenous (IV) fluid therapy (Meltzer, Hofmeyr \& Fivaz, 2006a), and applying water or snow to the animal's neck, belly, axilla and groin regions (Foster, 2005). In animals with body temperatures greater than $41^{\circ} \mathrm{C}$, the use of cold water enemas (Foster, 2005) and intravenous infusion of cold Ringer's lactate (Arnemo \& Fahlman, 2008) has been recommended. Fanning the animal and application of ice-packs may also be useful methods to reduce body temperature. Whole body fanning (Barwood, Davey, House \& Tipton, 2009) and the application of ice-packs to skin areas with large superficial blood vessels (Clements et al., 2002) effectively cooled hyperthermic humans, while ice- packs on the dorsal body surface cooled dogs (Canis lupus familiaris) after exercise (Kruk, Kaciuba-Uscilko, Nazar, Greenleaf \& Kozłowski, 1985).

For its convenience and ease of use in a field situation, water-dousing is the cooling method used most often in capture (Kock \& Meltzer, 2006; Meltzer, Burroughs \& Morkel, 2006b). While its efficacy has not been investigated systematically in capture-induced hyperthermia, its use is advocated. Cold water $\left(9^{\circ} \mathrm{C}\right.$ to $\left.16^{\circ} \mathrm{C}\right)$ dousing has been shown to cool horses (Equus ferus caballus) with exercise-induced hyperthermia (Kohn, Kenneth \& Kenneth, 1999). In the field it is impractical to carry large volumes of cold water, so the temperature of water used to douse wild animals varies and typically is close to that of ambient temperature. It is not known how effective warm (above $\sim 25^{\circ} \mathrm{C}$ ) water is, in comparison to cold water, in cooling hyperthermic animals.

While there is evidence to support the use of various cooling methods in hyperthermic humans and animals, usually under laboratory conditions, there has been no investigation or comparison of the efficacy of various methods for reducing capture-induced hyperthermia in wild animals. Using implanted temperature-sensitive data loggers to continuously and accurately measure core body temperature, we compared cooling by waterdousing at various temperatures, fanning, ice- pack application, mist spraying, and IV saline infusion, in captured hyperthermic antelope.

\section{MATERIALS AND METHODS}

All experimental and surgical procedures were approved by the Animal Ethics Screening Committee of the University of the Witwatersrand (clearance number 2008/34/04). Fourteen adult blesbok (Damaliscus pygargus phillipsi) at the National Zoological Garden's Biodiversity Conservation

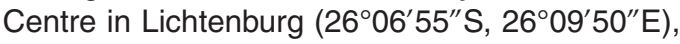
South Africa, were captured using a passive boma-capture technique (Kock \& Meltzer, 2006) a month before surgery. After capture the animals were housed in bomas (small enclosures of $10 \mathrm{~m} \times$ $5 \mathrm{~m}$ ), in groups of two to three animals per boma.

\section{Surgery}

During surgery, eight male $(49.0 \pm 10.0 \mathrm{~kg})$ and six female $(46.6 \pm 7.0 \mathrm{~kg})$ blesbok were surgically implanted with miniature temperature-sensitive data loggers (StowAway XTI, Onset Computer Corporation, Pocasset, Massachusetts, U.S.A.). Etorphine hydrochloride (3.0-3.5 mg intramuscularly, M99, Novartis, Johannesburg, South Africa) and azaperone (40-60 mg intramuscularly, Stresnil, Kyron Laboratories, Johannesburg, South Africa) were administered within a Pneu-dart (Type P, 3 cc, 13 gauge, $25 \mathrm{~mm}$ long wire barbed needle, Pneu-Dart, Williamsport, Pennsylvania, U.S.A.) projected by a dart gun (Sabi 500, SABI Werkswinkel t/a Magnum Arms, Nelspruit, South Africa) to induce anaesthesia (immobilization) in the blesbok for surgery. Once the animals were immobilized, anaesthesia was maintained with isoflurane (1-4\% in $100 \%$ oxygen, Isofor, Safe Line Pharmaceuticals, Johannesburg, South Africa), via a facemask. The site for data logger implantation was shaved and sterilized with chlorhexidine gluconate (Hibitane, Astra Zeneca, Johannesburg, South Africa) and $1 \mathrm{ml}$ of a local anaesthetic (Lignocaine Injection 2\%, Centaur Labs, Johannesburg, South Africa) was injected subcutaneously into the incision line area.

The miniature temperature-sensitive data logger was implanted, without tethering, into the abdomen through an incision in the left para-lumbar fossa. During surgery each animal received an injection of a long-acting penicillin (5-6 $\mathrm{ml}$ IM Peni La Phenix, $150 \mathrm{mg} / \mathrm{ml}$ procaine benzylpenicillin + $168 \mathrm{mg} / \mathrm{ml}$ benzathine benzylpenicillin, Virbac Animal Health, Centurion, South Africa), an analgesic anti-inflammatory $(1 \mathrm{ml}$ IV Phenylarthrite 
injectable solution, $200 \mathrm{mg} / \mathrm{ml}$ phenylbutazone, Bayer Animal Health, Centurion, South Africa), a Vitamin B injection (4 ml IM Rucenta Vitamin B Complex, Rucenta Medical Supplies, Johannesburg, South Africa) and a parasiticide $(0.5 \mathrm{ml}$ Dectomax subcutaneously, $1 \% \mathrm{~m} / \mathrm{v}$ doramectin, Pfizer Laboratories, Sandton, South Africa). Coloured and numbered ear-tags were attached to each animal for individual identification. After surgery, the wounds were sprayed with a topical antiseptic spray (Necrospray, Centaur Labs, Johannesburg, South Africa) and covered with an ectoparasiticide grease (Tick Grease, 0.025\% $\mathrm{m} / \mathrm{m}$ cypermethrin, Bayer Animal Health, Centurion, South Africa).

After surgery, the pharmacological action of etorphine was reversed with diprenorphine hydrochloride (M5050 7.2-8.4 mg IV, Novartis, Johannesburg, South Africa), the animals were released back into the bomas and their health was monitored closely for three days, and regularly thereafter. The blesbok were allowed one month to recover from the surgery before the commencement of our cooling experiments. A similar surgical and anaesthetic procedure was used to remove the loggers at the end of the study. After post-surgical recovery the blesbok were released back into the reserve.

\section{Body temperature measurements}

Core body temperature was measured with implanted miniature $(40 \times 40 \times 20 \mathrm{~mm})$ StowAway XTI temperature-sensitive data loggers. The data loggers recorded temperature continuously at 6-min intervals throughout the study, had a resolution of $0.04^{\circ} \mathrm{C}$ and a measurement range of $+32^{\circ} \mathrm{C}$ to $+46^{\circ} \mathrm{C}$. The loggers were calibrated against a high accuracy thermometer (Quat 100, Heraeus, Hanau, Germany), in an insulated water-bath, to an accuracy of $0.05^{\circ} \mathrm{C}$. The loggers, covered in an inert wax (Sasol wax EXP987, Sasol, Johannesburg, South Africa), were sterilized with formaldehyde vapour (Paraformaldehyde, Kyron Laboratories, Johannesburg, South Africa) in a sealed drum before implantation.

\section{Experimental procedure}

To reduce the number of interventions per animal, blesbok were divided into two groups, a 'waterdousing' group $(n=7)$ and an 'alternative methods' group $(n=7)$. The animals were darted at a weekly interval, during the southern hemisphere summer (January to February), on five occasions. The time of day at which chasing, darting and the cooling interventions took place was kept the same for each individual to reduce variability that may have occurred as a result of the animal's 24-h rhythm or body temperature. All interventions took place between 08:00 and 15:00.

To induce hyperthermia before the start of the cooling interventions, the blesbok from one boma (2-3 animals) were chased into a larger, adjoining enclosure $(10 \times 30 \mathrm{~m})$ where they were encouraged by people on the perimeter of the enclosure to run at a moderate pace for $10 \mathrm{~min}$. Thereafter, the animals were herded back to their boma. Following this 'chase', the animals were immediately darted (with $3.0-3.5 \mathrm{mg}$ etorphine and $40-60 \mathrm{mg}$ azaperone) and immobilized for the cooling intervention. Time to recumbency was $208 \pm 54 \mathrm{sec}-$ onds in the 'water-dousing' group and $273 \pm$ $146 \mathrm{~min}$ in the 'alternative methods' group.

After darting, each blesbok was immobilized for $30 \mathrm{~min}$. The blesbok were placed in sternal recumbency with the head held up and the nose pointing downwards. The animal was orientated with its head facing the sun so that the sun's rays fell on the animal's back evenly. Care was taken to ensure animals were not shaded by the researchers or the boma walls, and animals lay on the same sandy substrate for each trial. Skin temperature was measured by placing a thermistor (bead diameter 1.5 mm, 27 10K4A801, Onset Computer Corporation, Pocasset, Massachusetts, U.S.A.), attached to a washing-line peg, on the inside of the ear of the blesbok. Skin temperature was logged at a 2-min interval by a temperature-sensitive data logger (StowAway XTI, Onset Computer Corporation, Pocasset, Massachusetts, U.S.A.) at a resolution of $0.4^{\circ} \mathrm{C}$.

Within each group, all animals received five interventions, in a randomized cross-over design, at a weekly interval. Cooling interventions were initiated $5 \mathrm{~min}$ after immobilization, to allow for the monitoring equipment to be placed on the blesbok. Animals in both groups received a control intervention (no cooling) and a $28^{\circ} \mathrm{C}$ water-dousing intervention (to allow comparison between groups, and to evaluate the most common cooling practice of using water at ambient temperature). Testing before experimental trials, under our environmental conditions, revealed that water held in containers exposed to the environment had a mean temperature of $28^{\circ} \mathrm{C}$.

For animals in the 'water-dousing' group we compared the cooling efficacy of water at temperatures of $4^{\circ} \mathrm{C}, 17^{\circ} \mathrm{C}, 28^{\circ} \mathrm{C}$ and fanning following 
dousing of water at $28^{\circ} \mathrm{C}$ to a control intervention of no cooling. Animals were doused with $10 \mathrm{I}$ of water over the dorsal and lateral body surface (from the middle of the neck down towards the tail). The first 5 I was poured slowly over the animal and rubbed into the skin, from 5-10 min after the animal had been immobilized. The remaining 5 I was poured, and rubbed into the skin, 15-20 min after the start of immobilization. In this group of animals, we also examined if the addition of fanning to an animal doused with $28^{\circ} \mathrm{C}$ water $\left(28^{\circ} \mathrm{C}+\right.$ fanning $)$ improved the efficacy of cooling with $28^{\circ} \mathrm{C}$ water-dousing. Fanning was done by manually using a rigid plastic tray $(530 \mathrm{~mm} \times$ $380 \mathrm{~mm}$ ), which was waved up and down to produce a wind speed of about $1.2 \pm 0.6 \mathrm{~m} / \mathrm{s}$ (measured with a portable anemometer - Alnor GGA-65, Turku, Finland) from the start of dousing until the end of the immobilization.

For animals in the 'alternative methods' group we investigated effects of mist spraying, cold intravenous (IV) saline infusion, and ice-pack application. For the mist spray intervention, the animal received a fine mist spray of $28^{\circ} \mathrm{C}$ water, from a manual hand-held garden sprayer $(0.435 \mathrm{l} / \mathrm{min}$, Premium Pressurised Sprayer, Model G-2317, Shih Kuo, Taiwan) from a distance of about $100 \mathrm{~mm}$ from the body. The mist spray was applied to the dorsal and lateral body surface (from the middle of the neck down towards the tail) of the animal from 5-10 min and 15-20 min after the animal had been immobilized. For the IV infusion, 1 I of sterile isotonic saline (Adcock Ingram Critical Care, Johannesburg, South Africa) at $4^{\circ} \mathrm{C}$ was infused as fast as possible (over $12.8 \pm 1.5 \mathrm{~min}$ ) via an 18-gauge Jelco catheter (BD Insyte IV catheter, $1.3 \times 30 \mathrm{~mm}$, $105 \mathrm{ml} / \mathrm{min}, \mathrm{BD}$, New Jersey, U.S.A.) into the cephalic vein of the blesbok. For the ice-pack application, an 'ice-pack blanket' (Techni-Ice, Reusable Dry Ice Packs, HDR Model, Victoria, Australia) was placed over the dorsal and lateral body surface of the blesbok (from the middle of the neck down towards the tail) and in the groin and axilla areas (where there is less fur and good superficial blood supply), for $25 \mathrm{~min}$. The 'alternative method' group also contained a $28^{\circ} \mathrm{C}$ waterdousing intervention (same procedure as for the water-dousing group) and a control intervention (no cooling).

\section{Microclimate measurements}

Wet-bulb, dry-bulb and black globe temperatures (HO-007-02, Onset Computer Corporation,
Pocasset, Massachusetts, U.S.A.) were measured in the bomas. Wind speed (portable thermoanemometer, Alnor GGA-65, Turku, Finland) was measured by holding the sensor both at $1.5 \mathrm{~m}$ above the ground and $100 \mathrm{~mm}$ above the animal. Vapour pressure was determined from a psychrometric chart (Barenbrug 1974).

\section{Data analysis}

Complete data sets were retrieved from 12 animals. In the 'water-dousing group' two data loggers failed prematurely, reducing the sample size to five animals. For analyses, the time of the start of the cooling intervention was taken as time zero. The peak body temperature elicited after the chase procedure was the absolute maximum temperature within 30 min after time zero; this peak temperature always occurred just after the capture and the start of cooling in the recumbent blesbok. The minimum body temperature was calculated as the absolute minimum reached within 60 min from time zero. The change in body temperature after cooling (the magnitude of cooling) was calculated as the difference between the body temperature at time zero and the body temperature at $30 \mathrm{~min}$ and 1 hour later. The rate of cooling was calculated as the change in body temperature from the peak to the minimum body temperature (within $30 \mathrm{~min}$ ) divided by the time between these two points.

Results are reported as mean \pm standard deviation (S.D.) and $P<0.05$ was considered statistically significant. A paired Student's $t$-test for pairwise comparisons was used to compare body temperatures, as well as temperature differences between the skin and core, before and after darting. An unpaired Student's $t$-test was used to compare peak mean body temperatures between the two different groups. Repeated measures analysis of variance (RM-ANOVA) was used to compare peak, minimum and change in body temperature and rate of cooling in each group and a Newman-Keuls multiple comparisons test was used to detect significant differences between the interventions. We used GraphPad Prism version 6 for Windows (GraphPad Software, San Diego, U.S.A.) for statistical analyses.

\section{RESULTS}

\section{Environmental conditions}

Dry-bulb temperature, over all interventions, was $27.4 \pm 0.7^{\circ} \mathrm{C}$ for the 'water-dousing' group and 
$28.4 \pm 0.8^{\circ} \mathrm{C}$ for the 'alternative methods' group, while black globe temperature was $38.0 \pm 2.5^{\circ} \mathrm{C}$ for the 'water-dousing' group and $40.0 \pm 3.3^{\circ} \mathrm{C}$ for the 'alternative methods' group. Wet-bulb temperature was $22.8 \pm 0.8^{\circ} \mathrm{C}$ for the 'water-dousing' group and $23.1 \pm 0.4^{\circ} \mathrm{C}$ for the 'alternative methods' group. Wind speed in the boma, $1 \mathrm{~m}$ above the ground, was low and similar for both groups $(0.3 \pm 0.0 \mathrm{~m} / \mathrm{s}$ for the 'water-dousing' group, and $0.3 \pm 0.1 \mathrm{~m} / \mathrm{s}$ in the 'alternative methods' group). Vapour pressure was $2.5 \pm 0.2 \mathrm{kPa}$ for the 'waterdousing' group, and $2.6 \pm 0.1 \mathrm{kPa}$ in the 'alternative methods' group.

\section{Normal body temperature rhythm}

In undisturbed blesbok in the bomas (over 23 capture-free days), mean 24-hour body temperature was $38.8 \pm 0.4^{\circ} \mathrm{C}$, with a minimum body temperature of $37.9 \pm 0.1^{\circ} \mathrm{C}$ at about 08:30 each day and a maximum of $39.4 \pm 0.1^{\circ} \mathrm{C}$ at about 18:00.

\section{Body temperature changes in response to capture}

The chase and darting to mimic a capture procedure consistently induced a precipitous rise in body temperature (Fig. 1), above that of the body temperature before capture (peak body temperature was significantly higher than body temperature before capture $\left(t_{(11)}=10.79, P=0.0001\right)$. The peak body temperatures reached after capture were not different between individuals within the 'water-dousing' $\left(F_{(4,16)}=2.280, P=0.106\right)$ and those in the 'alternative methods' group $\left(F_{(4,16)}=\right.$ $0.365, P=0.831)$. These peak body temperatures were in the range of $41-42^{\circ} \mathrm{C}$ and were on average $41.4 \pm 0.5^{\circ} \mathrm{C}$ in the 'water-dousing' group and $41.2 \pm 0.4^{\circ} \mathrm{C}$ in the 'alternative methods' group; they were not different between the groups $\left(t_{(10)}=\right.$
1.56, $P=0.54)$. The mean time for the occurrence of the peak in body temperature after darting was $12.8 \pm 4.8 \mathrm{~min}$ in the 'water-dousing' group and $15.7 \pm 3.3 \mathrm{~min}$ in the 'alternative methods' group.

\section{Body temperature changes in response to cooling interventions}

In the control interventions, without any cooling method applied, the minimum body temperature exceeded $40^{\circ} \mathrm{C}$ in both groups of blesbok more than an hour after capture (Fig. 2A and Fig. 2B). Minimum body temperatures after all water-dousing interventions were significantly lower than minimum body temperature in the control intervention $\left(F_{(4,16)}=14.87, P<0.0001\right.$, Fig. 2A). The minimum body temperature, however, was not influenced by water temperature; minimum body temperature of the blesbok did not differ between the $4^{\circ} \mathrm{C}, 17^{\circ} \mathrm{C}$ and $28^{\circ} \mathrm{C}$ water-dousing interventions. Minimum body temperature after $28^{\circ} \mathrm{C}$ water-dousing with fanning also was lower than that of the control, but did not differ from the water-dousing interventions alone $\left(F_{(4,16)}=14.87, P<0.0001\right.$, Fig. $\left.2 \mathrm{~A}\right)$.

In the 'alternative methods' group, only the icepacks and the $28^{\circ} \mathrm{C}$ water-dousing interventions significantly $\left(F_{(4,16)}=7.431, P=0.0005\right.$, Fig. 2B) lowered minimum body temperature in comparison to the control. There was no difference between the minimum body temperatures in the blesbok after ice-pack application and $28^{\circ} \mathrm{C}$ waterdousing. However, the ice-packs significantly lowered body temperature compared to IV infusion and mist spray, while $28^{\circ} \mathrm{C}$ water-dousing resulted in a lower minimum temperature than did IV infusion.

Analysis of the magnitude of cooling, calculated as the absolute change in body temperature from

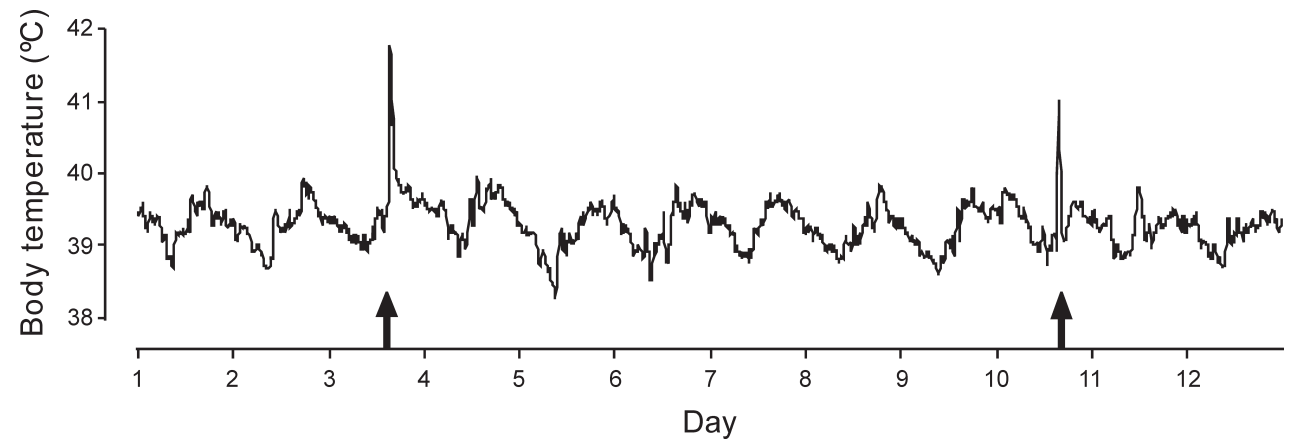

Fig. 1. The body temperature of one blesbok over 11 days in spring. On the third and tenth day the blesbok was chased and chemically immobilized (arrows) to perform cooling interventions. Note the precipitous rise in body temperature, of about $2^{\circ} \mathrm{C}$, at the time of the chase and chemical immobilization. 


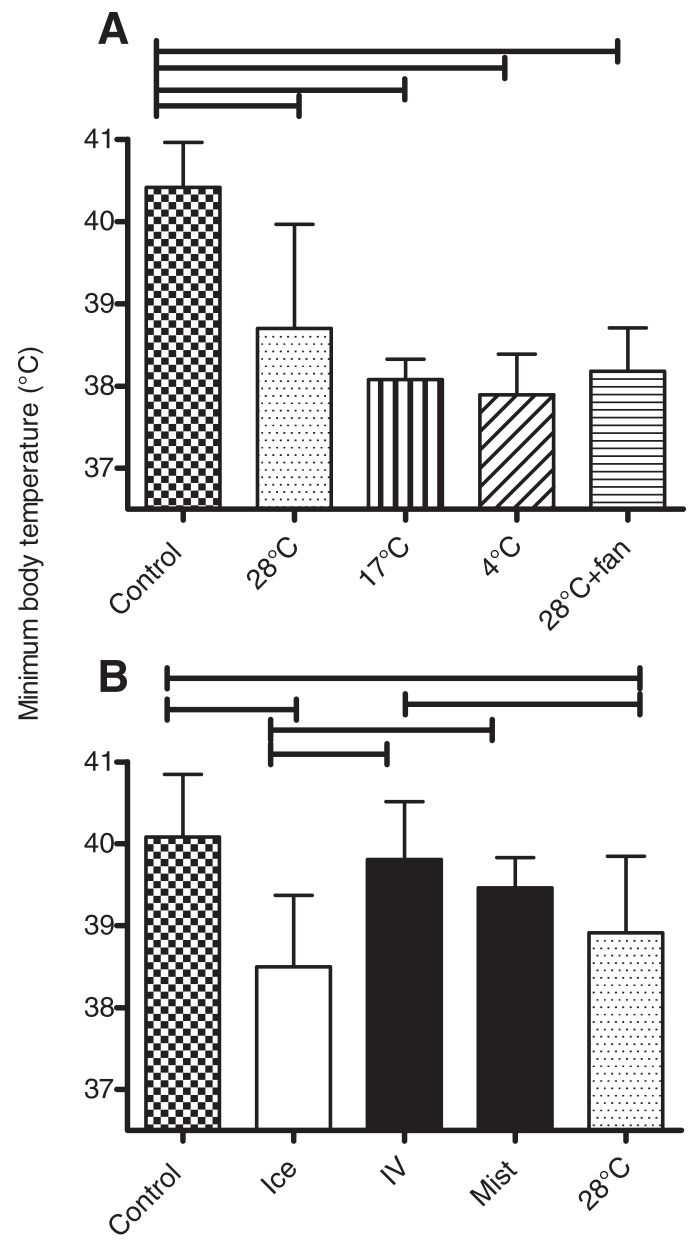

Experimental interventions

Fig. 2. Mean and S.D. of the minimum body temperatures reached within an hour from the start of cooling interventions. The top panel (A) illustrates the minimum body temperature reached following the water-dousing interventions in comparison to the control in lowering body temperature 1 hour after the start of the cooling intervention. The bottom panel (B) illustrates the minimum body temperature reached following alternative methods of cooling. The horizontal bars above the columns ( indicate significant differences between groups $(P<$ $0.05)$. The term IV refers to intravenous infusion of $4^{\circ} \mathrm{C}$ saline.

the start of cooling to 30 minutes (Fig. 3 left panels), and 1 hour later (Fig. 3 right panels), revealed similar results as did the patterns of minimum body temperature. After 30 minutes, all the water-dousing interventions led to a significantly greater change $\left(F_{(4,16)}=10.45, P=0.0002\right)$ in body temperature in comparison to the control (Fig. 3A). The magnitude of the change in body temperature did not differ between the water-dousing interventions of different water temperatures. A similar pattern occurred after an hour; however the magnitude of cooling was greater, at about $3^{\circ} \mathrm{C}$ for the waterdousing interventions (Fig. 3A vs Fig. 3B). There was no difference in the magnitude of cooling between $28^{\circ} \mathrm{C}$ water-dousing and $28^{\circ} \mathrm{C}$ waterdousing with the addition of fanning, at either 30 minutes or 1 hour.

In the 'alternative methods group', ice-packs, IV cold saline infusion and the $28^{\circ} \mathrm{C}$ water-dousing showed a significantly greater decrease in body temperature after 30 min compared to the control $\left(F_{(4,16)}=8.91, P=0.0001\right)$, with body temperature decreasing by about $1^{\circ} \mathrm{C}$ (Fig. $3 \mathrm{C}$ ). The mist spray was ineffective in lowering body temperature after 30 min and after 1 hour (Fig. 3C \& Fig. 3D). After 1 hour, body temperature was still significantly lower than in the control following the application of ice-packs and $28^{\circ} \mathrm{C}$ water-dousing $\left(F_{(4,16)}=12.12\right.$, $P=0.0001$, Fig. 3D). The change in body temperature after IV cold saline infusion, however, was no longer different to that of the control, in which body temperature had decreased slowly by about $1^{\circ} \mathrm{C}$ over the hour (Fig. 3D).

Water-dousing reduced body temperature regardless of water temperature. The minimum body temperature after cooling, and the fall in body temperature after $30 \mathrm{~min}$ and 1 hour, were not significantly different among $4^{\circ} \mathrm{C}, 17^{\circ} \mathrm{C}$, and $28^{\circ} \mathrm{C}$ water temperatures (Fig. 2A and 3A \& 3B). However, the rate at which the various water temperatures lowered body temperature did differ (Fig. 4A). In the 'water-dousing' group, body temperature fell more rapidly when animals were doused with $4^{\circ} \mathrm{C}$ water than when they were doused with $28^{\circ} \mathrm{C}$ water $\left(F_{(4,16)}=7.47, P=0.0014\right)$. When animals were doused with cold water $\left(4^{\circ} \mathrm{C}\right.$ and $\left.17^{\circ} \mathrm{C}\right)$ or with $28^{\circ} \mathrm{C}$ water with fanning, body temperature fell about three-fold as quickly as it did when they received the control intervention.

While $28^{\circ} \mathrm{C}$ water-dousing did not lower body temperature more rapidly than the control in the 'water-dousing group', it did do so in the 'alternative methods' group (Fig. 4B). However, the rate of cooling in this group of animals always was slow. After ice-pack application and $28^{\circ} \mathrm{C}$ water-dousing, body temperature of the blesbok decreased at a rate of about $0.05^{\circ} \mathrm{C} / \mathrm{min}$, significantly quicker than the rate of cooling in the control, which was about $0.03^{\circ} \mathrm{C} / \mathrm{min}\left(F_{(4,16)}=7.31, P=0.0021\right.$, Fig. 4B $)$, but much less than the cooling of about $0.1^{\circ} \mathrm{C} / \mathrm{min}$ seen in animals after $4^{\circ} \mathrm{C}$ water-dousing (Fig. 4A). The rate of fall in body temperature after the mist 


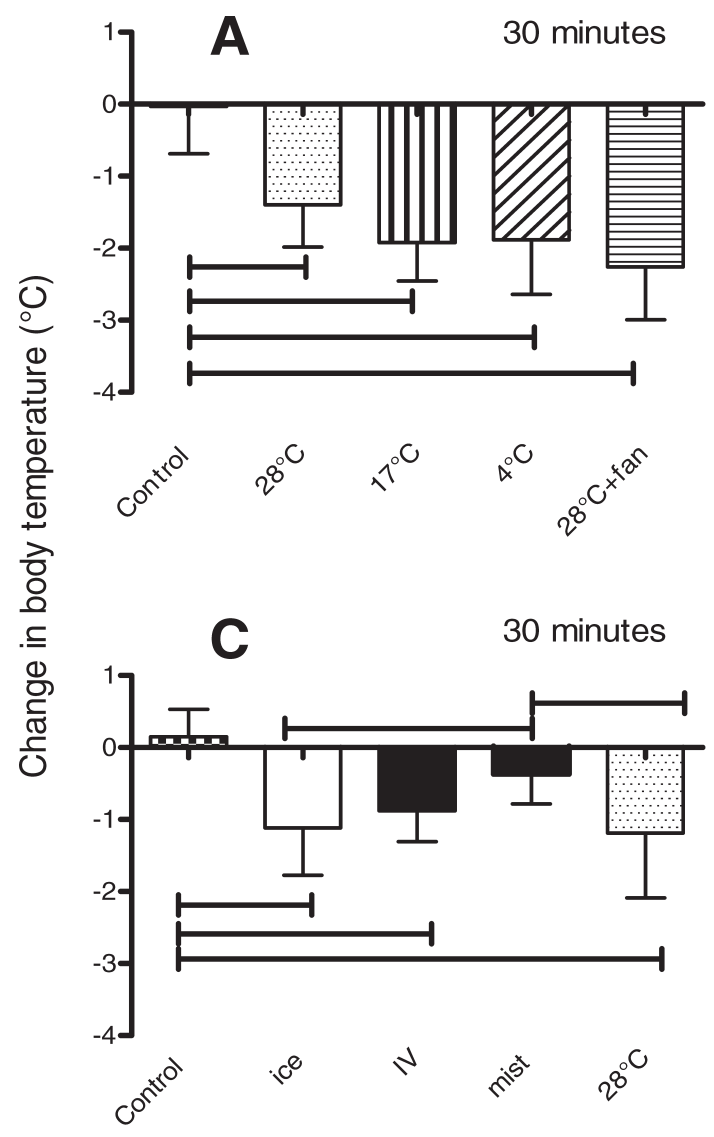

Experimental interventions

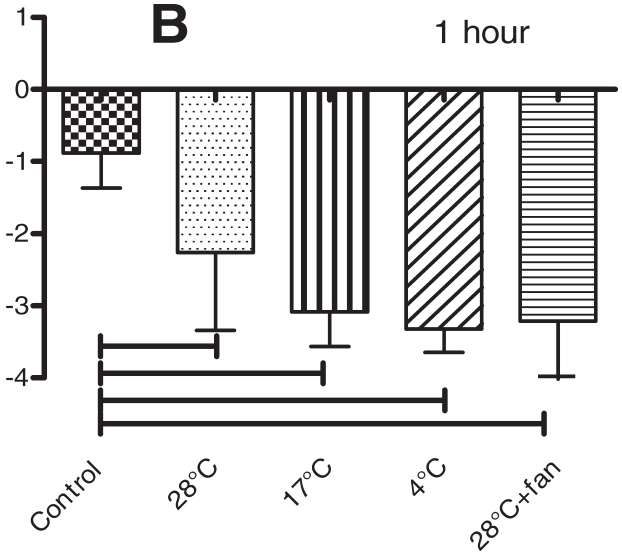

D 1 hour

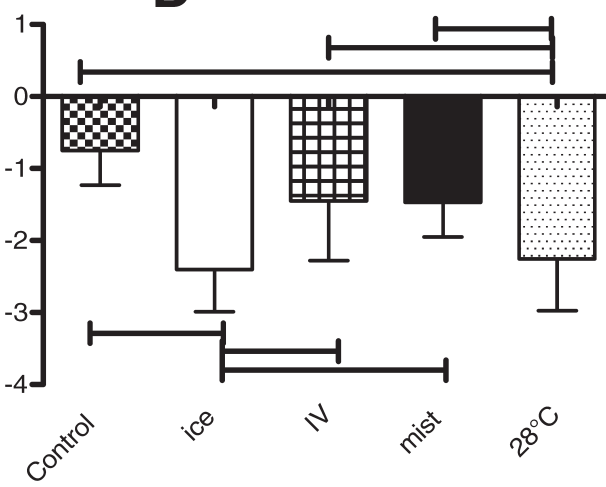

Experimental interventions

Fig. 3. Mean and S.D. of the magnitude of the change in temperature within 30 min (panels $\mathbf{A}$ and $\mathbf{C}$ ) and 1 hour (panels $\mathbf{B}$ and $\mathbf{D}$ ) following the start of the intervention. The solid horizontal bars above the columns $(\longmapsto)$ indicate significant differences between groups $(P<0.05)$. The term IV refers to intravenous infusion of $4^{\circ} \mathrm{C}$ saline.

spray and the IV infusion was not different to that of the control.

\section{Temperature difference between core and ear skin temperature}

The difference between the core (abdominal) and ear skin temperature at the end of cooling was $5.16 \pm 3.09^{\circ} \mathrm{C}$ in the 'water-dousing group' and $3.5 \pm 5.52^{\circ} \mathrm{C}$ in the 'alternative methods group' and these differences were no different to that at time zero $\left(t_{(4)}=1.73, P=0.098\right.$ 'water-dousing'; $t_{(6)}=0.23, P=0.824$ 'alternate methods'). The area under the curve for the temperature difference between the core and the ear skin from time zero to the end of cooling was also not different among the interventions in both the 'water-dousing interventions' $\left(F_{(4,16)}=0.149, P=0.96\right)$ and the 'alternative methods group' $\left(F_{(4,16)}=1.446, P=0.25\right)$.

\section{DISCUSSION}

As far as we are aware, this is the first study to compare the efficacy of various cooling techniques in lowering body temperature in captured hyperthermic antelope. We have shown that ice-pack application and water-dousing, with water temperature varying from $4^{\circ} \mathrm{C}$ to $28^{\circ} \mathrm{C}$, or with fanning added to $28^{\circ} \mathrm{C}$ water, were effective in returning the body temperature of hyperthermic blesbok, within an hour, to pre-capture levels. Intravenous infusion of $1 \mathrm{I}$ of cold saline also reduced body temperature but was less effective than were the water-dousing and ice-pack methods. Spraying $28^{\circ} \mathrm{C}$ mist over the animal had no effect; cooling was similar to that in the control in which no cooling method was applied.

One potential concern associated with cooling hyperthermic animals is the risk of hypothermia if 


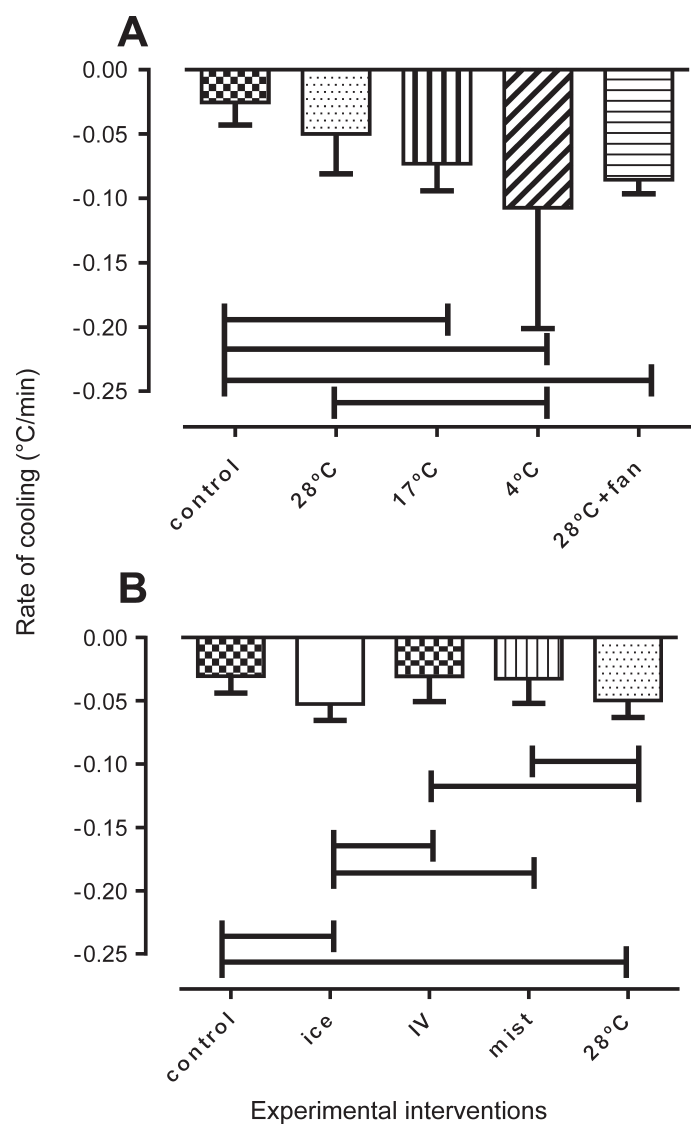

Fig. 4. Mean and S.D. of the rate of cooling within 30 minutes by each experimental intervention. The top panel (A) illustrates the rate of cooling following water-dousing and the bottom panel $(\mathbf{B})$ illustrates the rate of cooling following alternative cooling methods. The solid horizontal bars above the columns ( cate significant differences $(P<0.05)$. The term IV refers to intravenous infusion of $4^{\circ} \mathrm{C}$ saline.

body temperature continues to fall after the cooling intervention has ended. The cooled blesbok's body temperatures typically returned to normal within an hour after capture and there was no overshoot of body temperature to levels lower than normal. It is important, however, given the need to reduce morbidity and mortality in captured animals, that hyperthermic animals be cooled rapidly after capture. In most capture situations, animals are unlikely to be held or monitored for more than 30 min. We have shown that body temperature of blesbok returned to normal after 1 hour following water-dousing, water-dousing with fanning, and ice-pack application. However, these cooling interventions also elicited significant decreases in body temperature $30 \mathrm{~min}$ after the start of cooling, resulting in body temperatures below $39^{\circ} \mathrm{C}$, close to the normal 24-h average body temperature of $38.8^{\circ} \mathrm{C}$ for blesbok. While the minimum body temperature reached after cooling with $28^{\circ} \mathrm{C}$ and $4^{\circ} \mathrm{C}$ did not differ, $4^{\circ} \mathrm{C}$ water-dousing lowered body temperature more rapidly than did the tepid $28^{\circ} \mathrm{C}$ water. Often it may be impractical in the field to carry cold water; however, where rapid cooling of an animal is required, we have shown that water at $4^{\circ} \mathrm{C}$, or even $17^{\circ} \mathrm{C}$, was more effective than was water at $28^{\circ} \mathrm{C}$. However, the rate at which $28^{\circ} \mathrm{C}$ water-dousing lowered body temperature was improved, and was similar to that of cold water, if convective cooling through fanning was added. Our water-dousing interventions, which effectively and rapidly lowered body temperature (by 0.05 to $0.1^{\circ} \mathrm{C} / \mathrm{min}$ ), were applied for $10 \mathrm{~min}$ during the immobilization. Whether cooling applied over a shorter period, and through use of smaller volumes of water, is as effective in reducing body temperature as in our study remains to be determined. Similarly, whether our cooling protocols are effective when hyperthermia exceeds that experienced by our blesbok, or whether the cooling effect is dependent on the mechanisms resulting in the hyperthermia (i.e. stress-induced vs exertional-induced) needs to be elucidated.

Body temperatures that exceed $41-42^{\circ} \mathrm{C}$ are known to cause cellular damage in most mammals (Grint, Gorvy \& Dugdale, 2007; Haskins, 1995), and temperatures greater than $43^{\circ} \mathrm{C}$ are believed to result in death of wildlife during capture procedures (Kock \& Meltzer, 2006). The extent of tissue damage and physiological malfunction depend not only on the magnitude of the hyperthermia but also on its duration (Proulx, Ducharme \& Kenny, 2003). In humans, the primary objective of treatment for hyperthermia is to reduce body temperature to a safe level as quickly as possible (Proulx, Ducharme \& Kenny, 2003). At present, there are no data to indicate what duration of hyperthermia is harmful to an animal with capture-induced hyperthermia, or the magnitude, or rate of cooling that is required to reduce the pathophysiological consequences of this hyperthermia. Therefore, we believe the premise should be that the most effective cooling method should be instituted as soon as possible and should be applied until body temperatures approach near normal values.

In addition to the difficulty of keeping water cold in the field, a potential limitation of applying cold water to an animal's surface is that the cold stimulus may elicit vasoconstriction (Daanen, 2003), lead- 
ing to an attenuated fall in body temperature. Such vasoconstriction may be reflected by an increased difference between core body temperature and skin temperature. We found, however, that the difference between core temperature and ear skin temperature remained constant, at about $5^{\circ} \mathrm{C}$, throughout the cooling interventions and did not differ across the various cooling interventions. It appears unlikely, therefore, that cold water dousing led to a change in vasomotor tone that altered the efficacy of the cooling. Azaperone, used in the dart to immobilize the animals, has alpha ${ }_{1}$ adrenergic receptor antagonist properties that may have elicited vasodilation (Meltzer, Burroughs \& Morkel, 2006b), potentially countering any cold-induced vasoconstriction, but any drug effects would have been similar in all interventions.

The finding that water-dousing effectively lowered body temperature supports the common practice in field conditions of pouring water over captured animals and rubbing the water into the hair (Foster, 2005; Meltzer, Hofmeyr \& Fivaz, 2006a; Arnemo \& Fahlman, 2008). Non-anaesthetized hyperthermic horses have been effectively cooled with $6^{\circ} \mathrm{C}$ and $15^{\circ} \mathrm{C}$ water-dousing (Marlin et al., 1998; Kohn, Kenneth \& Kenneth, 1999). In the field it is not always possible to regulate the temperature of water, or to keep water cold. In southern Africa, where we worked, water stored in a container exposed to the environment is likely to be warm, even in winter, as a result of high solar radiation. Importantly, we have shown that even water at $28^{\circ} \mathrm{C}$ can be used to lower the body temperature of hyperthermic antelope after capture.

Our findings were similar to our expectations that colder water $\left(4^{\circ} \mathrm{C}\right.$ and $\left.17^{\circ} \mathrm{C}\right)$ would decrease the body temperature quicker than would $28^{\circ} \mathrm{C}$ water because of an increased conductive cooling power resulting from a greater temperature difference between the water and the animal (Jessen, 2001; Willmer, 2005). We also predicted that dousing the blesbok with $28^{\circ} \mathrm{C}$ water with fanning would be more effective in cooling the animals than would $28^{\circ} \mathrm{C}$ water-dousing alone, because fanning increases heat loss through convection and evaporation of water off the animal (Jessen, 2001). However, we found no difference when we doused the animals only with $28^{\circ} \mathrm{C}$ water compared to when we fanned the animals while dousing them with $28^{\circ} \mathrm{C}$ water. We fanned the blesbok with a rigid sheet of plastic to simulate field practice, and generated a wind speed of about $1.2 \mathrm{~m} / \mathrm{s}$ over the animal. This wind speed was possibly too low; the recommendation for alleviating heat stress in cattle (Bos taurus) is a wind speed of 2 to $4 \mathrm{~m} / \mathrm{s}$ (Gaughan, Binns \& Lott, 2004). Generating such high wind speeds to improve convective cooling may be impractical in the field, although situations where animals are subsequently translocated in ventilated vehicles may facilitate additional convective cooling.

Guidelines for cooling captured animals also recommend the use of cold IV infusions, mist sprays and packing of ice under the axilla, groin and tongue (Foster, 2005; Meltzer, Hofmeyr \& Fivaz, 2006a; Arnemo \& Fahlman, 2008). We investigated some of these methods as alternatives to water-dousing. Because the placement of ice-packs to only the axilla and groin is ineffective in decreasing body temperature in humans (Smith, 2005), we placed ice-packs over the body surface as well as ice-packs in the axilla and groin and found that these cooled the animals effectively by decreasing body temperature in a manner similar to that of water-dousing.

Cold IV fluids also have been used in the field to cool wild animals (Foster, 2005; Meltzer, Hofmeyr \& Fivaz, 2006a; Arnemo \& Fahlman, 2008). In humans, $4^{\circ} \mathrm{C}$ isotonic saline has been used to reduce body temperature by between $1^{\circ} \mathrm{C}$ (Moore, Callaway \& Hostler, 2008) and $2.5^{\circ} \mathrm{C}$ (Rajek et al., 2000). Infusion of 11 of cold saline in blesbok led to a fall in body temperature after $30 \mathrm{~min}$ of about $1^{\circ} \mathrm{C}$. The infusion of cold saline was not as effective in lowering body temperature as were waterdousing and ice application. Increasing the volume of infused saline is likely to improve cooling, but infusing a higher volume is impractical and increases the risk of pulmonary oedema (Bouchama, Dehbi \& Chaves-Carballo, 2007). Rather than being used as a first-line cooling approach, IV infusion may be useful in situations of severe hyperthermia, where it could be used in combination with other cooling techniques, such as water-dousing, to cool an animal more rapidly.

The only method that was completely ineffective in lowering body temperature of our blesbok was mist spraying. Mist sprays have been recommended for cooling hyperthermic animals, on the basis that spraying allows better soaking of the animal's pelage than does dousing, and because of an erroneous belief that sprayed water is cooled by evaporation once the water droplets are expelled from the sprayer. Our study does not support these ideas; even though spraying did soak the animals pelage, spraying water at $28^{\circ} \mathrm{C}$ was less effective 
than was the more practical method of dousing an animal with $28^{\circ} \mathrm{C}$ water. Ice-packs also restored body temperature of hyperthermic animals to pre-capture levels but carrying water is far less cumbersome and difficult than is transporting and maintaining ice-packs in the field. We therefore recommend, at least in species of similar size and pelage to blesbok, that water-dousing is the most practical and effective method to cool an animal with capture-induced hyperthermia. Although no more effective than tepid water in cooling an animal over 30-60 min, cold water will cool an animal quicker. In circumstances where it is difficult to carry cold water, and where there is a need to cool an animal rapidly, the addition of convective cooling through fanning is likely to be beneficial if adequate air movement is generated.

\section{ACKNOWLEDGEMENTS}

We thank the National Zoological Gardens for the use of their facilities and support from staff at the Lichtenburg Game Breeding Centre, volunteers from the Brain Function Research Group for assistance with data collection, and the staff of the Central Animal Service for assistance with surgery. This study was funded by the National Research Foundation, South Africa.

\section{REFERENCES}

Arnemo, J.M. \& Fahlman, A. (2008). Biomedical protocols for the free-ranging brown bears, gray wolves, wolverines and lynx. Hedmark University College, Norway and Swedish University of Agriculture Sciences, Sweden.

Barenbrug, A.W.T. (1974). Psychometry and psychrometric. Cape Town, Chamber of Mines of South Africa: Cape and Transvaal Printers.

Barwood, M.J., Davey, S., House, J.R. \& Tipton, M.J. (2009). Post-exercise cooling techniques in hot, humid conditions. European Journal of Applied Physiology, 107, 385-396

Bouchama, A., Dehbi, M. \& Chaves-Carballo, E. (2007). Cooling and hemodynamic management in heatstroke: practical recommendations. Critical Care, 11, R54

Cattet, M.R.L., Christison, K. \& Caulkett, N.A. (2003). Physiological responses of grizzly bears to different methods of capture. Journal of Wildlife Diseases, 39, 649-654

Clements, J., Casa, D., Knight, J., McClung, J.M., Blake, A.S., Meenen, P.M., Gilmer, A.M. \& Caldwell, K.A. (2002). Ice-water immersion and cold-water immersion provide similar cooling rates in runners with exercise-induced hyperthermia. Journal of Athletic Training, 37, 146-150

Daanen, H.A. (2003). Finger cold-induced vasodilation: a review. European Journal of Applied Physiology, 89, $411-426$
Drew, M.L. (1996). The use of a tympanic membrane thermometer for assessing hyperthermia in bighorn sheep. Journal of Wildlife Diseases, 32, 512-516

Foster, CL. (2005). Wild sheep capture guidelines. Biennual Symposium of Northern Wild Sheep and Goat Council, 14, 211-282.

Fuller, A., Moss, D.G., Skinner, J.D., Jessen, P.T., Mitchell, G. \& Mitchell, D. (1999). Brain, abdominal and arterial blood temperatures of free-ranging eland in their natural habitat. Pflugers Archive - European Journal of Physiology, 438, 671-680

Ganhao, M., Hattingh, J. \& Pitts, N. (1988). Physiological responses of blesbok, eland and red hartebeest to different capture methods. South African Journal of Wildlife Research, 18,134-136

Gaughan, J., Binns, P. \& Lott, S. (2004). Wetting cattle to alleviate heat stress on ships. Meat and Livestock Australia Limited, LiveCorp. Report No: Live.219

Grint, N., Gorvy, D. \& Dugdale, A. (2007). Hyperthermia and delayed-onset myopathy after recovery from anesthesia in a horse. Journal of Equine Veterinary Science 27, 221-227

Haskins, S.C. (1995). Thermoregulation, hypothermia, hyperthermia. In SJ. Ettinger. \& EC. Feldman (Eds), Veterinary internal medicine (4th edition) (pp. 26-30). Philadelphia. U.S.A. W.B Saunders Company.

Jessen, C. (2001). Temperature regulation in humans and other mammals. Berlin, Germany: Springer-Verlag.

Kock, M.D., Jessup, D.A., Clark, R. \& Franti, C.E. (1987). Effects of capture on biological parameters in freeranging bighorn sheep (Ovis canadensis): evaluation of drop-net, drive-net, chemical immobilization and the net gun. Journal of Wildlife Diseases, 23, 641651

Kock, M. \& Meltzer, D. (2006). Stress and capture related death. In M. Kock, D. Meltzer. \& R. Burroughs (Eds), Chemical and physical restraint of wild animals: a training and field manual for African species (pp. 68-76). Greyton, South Africa: International Wildlife Veterinary Services (Africa).

Kohn, C.W., Kenneth, W.H. \& Kenneth, H.M. (1999). Evaluation of washing with cold water to facilitate heat dissipation in horses exercised in hot, humid condition. American Journal of Veterinary Research, 60, 299-305

Kosaka, M., Yamane, M., Ogai, R., Katoa Y., Ohnishia N. \& Simon, E. (2004). Human body temperature regulation in extremely stressful environment: epidemiology and pathophysiology of heat stroke. Journal of Thermal Biology, 29, 495-501

Kruk, B., Kaciuba-Uscilko, H., Nazar, K., Greenleaf, J.E. \& Kozłowski, S. (1985). Hypothalamic, rectal and muscle temperatures in exercising dogs: effect of cooling. Journal of Applied Physiology, 58, 14441448

Marlin, D.J., Scott, C.M., Roberts, C.A., Casas, I., Holah, G. \& Schroter, R.C. (1998). Post exercise changes in compartmental body temperature accompanying intermittent cold water cooling in the hyperthermic horse. Equine Veterinary Journal, 30, 28-34

Meltzer, D., Hofmeyr, M. \& Fivaz, B. (2006a). Ancillary treatments in wildlife capture and care. In M. Kock, D. Meltzer. \& R. Burroughs (Eds), Chemical and physi- 
cal restraint of wild animals: a training and field manual for African species (pp. 245-249). Greyton, South Africa: International Wildlife Veterinary Services (Africa).

Meltzer, D., Burroughs, R. \& Morkel, P. (2006b). Applied pharmacology. In Kock, D. Meltzer. \& R. Burroughs (Eds), Chemical and physical restraint of wild animals: a training and field manual for African species (pp. 43-67). Greyton, South Africa: International Wildlife Veterinary Services (Africa).

Meyer, L.C.R., Fick, L.G., Matthee, A., Mitchell, D. \& Fuller, A. (2008a). Hyperthermia in captured impala (Aepyceros melampus): a fright not a flight response. Journal of Wildlife Diseases, 44, 404-416

Meyer, L.C.R., Hetem, R.S., Fick, L.G., Mitchell, D. \& Fuller, A. (2008b). Thermal, cardiorespiratory and cortisol responses of impala (Aepyceros melampus) to chemical immobilisation with four different drug combinations. Journal of the South African Veterinary Association, 79 (3), 121-129
Moore, T.M., Callaway, C.W. \& Hostler, D. (2008). Core temperature cooling in healthy volunteers after rapid intravenous infusion of cold and room temperature saline solution. Annals of Emergency Medicine, 51, 153-159

Proulx, C.I., Ducharme, M.B. \& Kenny, G.P. (2003). Effect of water temperature on cooling efficiency during hyperthermia in humans. Journal of Applied Physiology, 94, 1317-1323

Rajek, A., Greif, R., Sessler, D.I., Baumgardner, J., Laciny, S. \& Bastanmehr, H. (2000). Core cooling by central venous infusion of ice-cold (4 degrees $C$ and 20 degrees $\mathrm{C}$ ) fluid: isolation of core and peripheral thermal compartments. Anesthesiology, 93, 629-637.

Smith, J.E. (2005). Cooling methods used in the treatment of exertional heat illness. British Journal of Sports Medicine, 39, 503-507

Willmer, P., Stone, G. \& Johnston, I. (2005). Environmental physiology of animals. Victoria, Australia: Blackwell Publishing. 